\title{
Lessons learned from an intercalibration exercise on the quantification and characterisation of microplastic particles in sediment and water samples
}

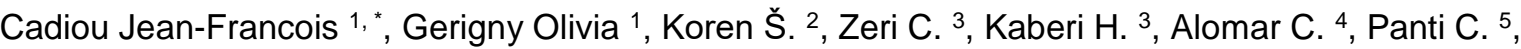 \\ Fossi M.C. ${ }^{5}$, Adamopoulou A. ${ }^{3}$, Digka N. ${ }^{3}$, Deudero S. ${ }^{4}$, Concato M. ${ }^{4}$, Carbonell A. ${ }^{4}$, Baini M. ${ }^{5}$, \\ Galli M. ${ }^{5}$, Galgani Francois ${ }^{1}$
}

1 Institut Français de Recherche pour l'Exploitation de la Mer (Ifremer), Zone Portuaire de Bregaillon CS 20 330, La Seyne-sur-Mer 83507, France

2 Institute for Water of the Republic of Slovenia (IWRS), Dunajska cesta 156, SI-1000 Ljubljana, Slovenia

${ }^{3}$ Hellenic Centre for Marine Research (HCMR), Institute of Oceanography, 19013 Anavyssos, Attica, Greece

4 Instituto Español de Oceanografía, Centro Oceanográfico de Baleares, Muelle de Poniente s/n, 07015 Palma de Mallorca, Spain

${ }^{5}$ Department of Physical Sciences, Earth and Environment, University of Siena, Via P.A. Mattioli, 4, 53100 Siena, Italy

*Corresponding author : Jean-François Cadiou, email address : jean.francois.cadiou@ifremer.fr

\begin{abstract}
:
An intercalibration exercise on the characterisation of microplastics in marine sediment and water samples was carried out among five laboratories involved in the implementation of the Marine Strategy Framework Directive (MSFD) in their country. The samples were prepared by mixing cleaned natural sediment and sea water with microplastics sets made of particles of various polymers, shapes and colours. Overall, the errors on total counts were under $25 \%$ in absolute value. The risk of non-detection and loss of particles is greater than the risk of contamination during sample analysis. Significant differences are observed among particle types. It appears difficult to obtain reliable and comparable data on the colour of microplastics. A comparison of the errors with regards to the protocols used led to recommend $\mathrm{NaCl}[1.2 \mathrm{~g} / \mathrm{cm} 3]$ density separation for sediment and one filtering step $(200 \mu \mathrm{m})$. The operators' experience appears as a key factor for the quality of the results.
\end{abstract}

\section{Highlights}

- Underestimation is the most frequent cause of error on the total counts $>$ Recommended protocol: $\mathrm{NaCl}$ density separation for sediment, filtering $200 \mu \mathrm{m}$. Operators' experience is a key quality factor $>$ Data on colour is not reliable and comparable Obtaining clean natural sediment reference material is an issue FT-IR analysis is useful to remove ambiguities on mineral and biological particles

Keywords : Microplastics, Intercalibration, Protocols, Sediment, Seawater 


\section{1 - Introduction}

Pollution of the marine environment by plastic waste is today acknowledged as a global problem (Jambeck et al., 2015; Lebreton et al., 2012). The worldwide use and mass production of plastic (Thompson et al., 2009) in the last century has led to the accumulation of this type of debris in the marine environment (Rochman et al., 2013). Plastics accumulated in the marine environment might pose many threats to the marine ecosystems by directly polluting them (Stefatos et al., 1999; Sutherland et al., 2010), but they can also impact species inhabiting them by causing, for example, strangulation and suffocation problems (Galgani et al., 2014). In addition, smaller plastic particles can be ingested by marine organisms arising the potential of biological effects (Darmon et al., 2017; Giani et al., 2019) and effects linked to chemical contamination such as endocrine disruption, histopathological changes or alteration of responses of immune system (Rochman et al., 2013; Limonta et al., 2019). These threats can come from both macro-plastics and microplastics (Law and R., 2014; Li et al., 2016) and adverse effects have been demonstrated by numerous studies (Barboza and Gimenez, 2015; Caruso, 2019; Guo and Wang, 2019; Peng et al., 2020; Wesch et al., 2016).

Microplastics (MP) are defined as small plastic particles < 5 mm (Arthur et al., 2009; GESAMP, 2019) resulting either from the fragmentation of macro-plastics (secondary microplastics) or directly from industrial production (primary microplastics, e.g. pellets). These particles, highly persistent in the environment (Alimba and Faggio, 2019), are present in all marine matrices: water, sediment, biota, (Li et al., 2016; Peng et al., 2020; Sharma and Chatterjee, 2017) from the coastline to offshore areas, including deep sea submarine canyons (Alomar et al., 2017; Spedicato et al., 2019). An increasing number of studies are also investigating the consequences of chemical contamination of the marine ecosystem by substances such as bisphenol $A$ and phthalates added during the manufacture of certain plastics (Vered et al., 2019).

Seawater and sediments are the matrices in which MP are most sampled and studied. However, sampling conditions (weather, currents, wind, sea state), sampling location; analytical and extraction methods; classification, identification and counting protocols; expression of results (e.g. units) show a high variability. Consequently, the lack of harmonisation in methods is a very limiting factor for the 
comparability and the reproducibility of the results making it difficult to jointly analyse and interpret Therefore, even though the extraction and characterization methods have been reviewed (GESAMP, 2019), several studies have highlighted the need to progress in the standardisation of sampling and analysis methodology by defining simple, effective and reproducible protocols (Cincinelli et al., 2019; Galgani, 2015; Galgani et al., 2013b; Prata et al., 2019a).

The Mediterranean is considered one of the most polluted seas in Europe (Gerigny et al., 2019; loakeimidis et al., 2017; loakeimidis et al., 2014) mainly due to its semi-enclosed nature and coastal urbanisation, intense shipping, high tourist pressure, industrial development, large river inputs and significant fishing activity (UNEP, 2016). It has been proven that all compartments of the Mediterranean marine ecosystems (water, sediment and biota) are polluted by MP (de Haan et al., 2019; Giani et al., 2019) and numerous studies show that their distribution and composition are heterogeneous, with marked geographical differences between sub-basins (Cincinelli et al., 2019).

Plastic pollution in the Mediterranean basin is considered a key issue in environmental policies at European level as well as by the Regional Sea Conventions such as OSPAR and the Barcelona Convention (UNEP, 2017). Elaborating methods and measures to better assess and combat this pollution, including MP, is therefore considered as a priority (Maes et al., 2019) for the implementation of the European Plastics Strategy and the Marine Strategy Framework Directive (EU, 2008, MSFD).

In the MSFD, MP are included as an aspect to be measured within Descriptor 10 of the Good Environmental Status (GES) of this directive. In the Commission decision (EU) 2017/848, which lays down criteria and methodological standards on GES of marine waters, specifications and standardised methods for monitoring and assessment of marine litter (Galgani et al., 2013a), the microplastics are included as a primary criterion: D10C2 - "The composition, amount and spatial distribution of micro-litter on the coastline, in the surface layer of the water column, and in seabed sediment, are at levels that do not cause harm to the coastal and marine environment". The specifications and standardised methods for monitoring and assessment of marine micro-litter, according to this criterion, require monitoring of water and sediment samples.

Recent studies (GESAMP, 2019; Michida et al., 2019) have reviewed and evaluated sample processing and analytical methods for quantifying MP in the marine environment. However, there is still no standardised protocols available for analysis of micro-litter in (sea) water and (marine) sediment samples. In the European Union, it is up to each Member State (MS) to decide which protocol to use in order to perform the monitoring of micro-litter when implementing the MSFD. The only common criterion for all the MS is to monitor particles smaller than $5 \mathrm{~mm}$. Therefore, standardisation and intercalibration of the existing protocols for sampling micro-litter in sea water and marine sediments are key issues to be addressed by the MS, if greater comparability between monitoring results is to be achieved (Gago et al., 2016, Crise et al., 2015).

This paper presents the results of an intercalibration exercise (ICE) on MP identification and analysis in water and sediment samples, performed by five laboratories involved in the MSFD implementation in the Mediterranean region. The aim of the research was to compare the methods of identifying, counting and classifying the MP in seawater and sediment samples following the MSFD monitoring recommendations (Galgani et al., 2013b). The size of MP considered in this ICE ranged from $300 \mu \mathrm{m}$ to $5 \mathrm{~mm}$ according to these recommendations. Unlike Isobe et al. (2019), who carried out recently a similar ICE focusing on total counts and particle size, the present study focuses on total counts, type/shape and colour of MP and FTIR validation of particles identified. Moreover, the aim of this 
work is to identify and highlight weaknesses and strengths of the different methodologies used for the analysis of MP in seawater and sediment samples and to provide future recommendations in accordance with the lessons learnt from the present ICE.

\section{2 - Material and methods}

For the intercalibration exercise, five laboratories from five European Mediterranean countries have participated to the intercalibration exercise: Hellenic Centre for Marine Research/Institute of Oceanography (HCMR), Greece; the Balearic Centre of Oceanography from the Spanish Institute of Oceanography (IEO), Spain; Ifremer/Laboratoire Environnement Ressources-Provence Azur Corse (LER/PAC), France; Institute for Water of the Republic of Slovenia (IWRS)/in-house laboratory, Slovenia; and University of Siena/Biomarkers laboratory, Italy.

\section{Preparation of the reference samples for the intercalibration exercise}

The reference samples, i.e. mixtures of clean water or sediment with MP sets, were prepared by the Ifremer/LER/PAC laboratory. For impartiality purposes, the operator who performed the sample preparation was not involved in the posterior analysis phase of the ICE. In order to prevent contamination during the preparation process at the laboratory, operators involved in the manipulation of samples were equipped with white cotton labcoats and nitrile gloves. Sandy beach sediment with few fine $(<300 \mu \mathrm{m})$ particles and without mud and seawater were selected as matrix types. For each matrix, samples were prepared in two concentration ranges according to the count of particles: the first with a low concentration of MP (between 70 and 100 particles) and the second with a high concentration (between 130 and 170 particles). Although the number of MP differs from one sample to another, this range is considered large enough to obtain significant and comparable errors.

\section{Preparation of microplastic particles}

In order to prepare the MP sets added to the reference samples, various plastic parent objects/materials were used: Plastic sheets (PET, PVC, PC) and pellets (HDPE, PP, PVC) supplied by manufactures; everyday plastic objects of different degradation states such as bags, gloves, cups, bottle stoppers, food containers, insulation foam as well as fishing lines (diameter: $200 \mu \mathrm{m}$ ). Parent materials were hand broken down into small pieces of different sizes. By combining these pieces with pellets supplied by the manufacturers, MP sets including particles of various shapes which are commonly found in the marine environment (fragments, pellets, filaments, films and foam) were composed. Particles used were of several colours: blue, orange, red, white and transparent. The size range of the particles varied from $300 \mu \mathrm{m}$ to $5 \mathrm{~mm}$, i.e. according to microplastics definition (Galgani et al., 2013b). However, a few particles in the range 5-10 mm (i.e. meso plastics) were also included. The specific size/dimensions of each particle included in the reference samples was not recorded. Although the resulting particle sets were not identical, and the preparation method can be considered crude, compared to the one used by Isobe et al, (2019), it allowed us to produce visually similar MP sets at a reasonable cost.

For each type of matrix and MP concentration, the number of particles per type was different. In all the MP sets, the dominant category was fragments, with a proportion always exceeding $47 \%$ of the total number of particles. Each sample was coded with a number and the exact characteristics of the MP associated to each sample, as well as the total weight of the particle set, were recorded.

Sediment reference sample preparation 
For the preparation of sediment samples, beach sediment was collected in the bay of Toulon. MP were separated and removed by spiking with a saturated $\mathrm{NaCl}$ solution $\left(1.2 \mathrm{~g} \mathrm{~cm}^{-3}\right)$, agitating for 2 minutes and then, after 48 hours, by sieving the supernatant solution through a $100 \mu \mathrm{m}$ sieve (Galgani et al., 2013b). This procedure was repeated five times in order to remove all the existing MP in the sediment. Finally, the excess water was removed and the sediment was oven dried at $40{ }^{\circ} \mathrm{C}$ for one week. For each sediment reference sample, a MP set was added into a $500 \mathrm{ml}$ glass bottle and mixed with $250 \mathrm{~g}$ of cleaned sediment, $50 \mathrm{ml}$ absolute ethanol and seawater filtered through $100 \mu \mathrm{m}$ sieve.

\section{Water reference sample preparation}

Seawater was taken from the bay of Toulon and filtered through $100 \mu \mathrm{m}$. For each reference sample, a MP particle set was added into a $500 \mathrm{ml}$ glass bottle and then filled with seawater mixed with absolute ethanol (5\%) for preservation.

Biological contamination of reference samples

In order to prepare samples with high similarity to the natural matrix found in real samples, biological material was added in both types of reference samples. This material was composed of pieces of Posidonia oceanica leaves, mussel shells and other shells that was rinsed with distilled water and of zooplankton sorted using binoculars. This ensured that this biological material was free of MP.

\section{Guidelines for the execution of the intercalibration exercise}

Two reference sediment samples and two water samples were sent to each laboratory participating in the ICE. Guidelines regarding the information requested and the reporting of the results were given. This included, in particular the information on total item counts, types and colours of MP for each sample. MP type and colour categories were based on the EMODnet classification (Galgani et al., 2017). This classification defines seven types of microlitter particles: fragments, pellets, filaments, films, styrofoam, non-plastic and items (Table S1, Suppl. Material); and nine colour classes: black/grey, blue/green, brown/tan, white, cream, yellow, orange/pink/red, transparent and opaque. This ninth class has been changed recently from opaque to multicolour (Table S2, Suppl. Material). Nevertheless, the opaque class was used for the present ICE.

Each laboratory was asked to perform the analysis following the protocol usually applied for the determination of microlitter in sediment and water samples. In this 'blind analysis' step, the reference values were not available to the laboratories involved in the ICE.

Moreover, four out of the five laboratories participating in the ICE have also provided the total weight of MP.

\section{Analytical methods used by the participating laboratories}

Protocol details along with specific adjustments used by each laboratory in the ICE are presented in Table 1. In general, the pre-processing of sediment samples varied more amongst laboratories in comparison to the water samples. This was related mostly to the different flotation reagent used ( $\mathrm{Nal}$ or $\mathrm{NaCl}$ ) during the density separation step. Other differences affecting both sediment and water samples analysis relate to the size of the separation sieves used, the use of an organic matter digestion reagent and the contamination control (e.g. procedural blanks, use of open Petri dish for monitoring airborne contamination). 
Table 1: Protocols used for analysis of sediment and water samples by each of the participating laboratories, and the details of possible problematic steps in the analysis of microplastics.

\section{Sediment Samples}

\begin{tabular}{|c|c|c|c|c|c|}
\hline Laboratory & L1 & L2 & L3 & L4 & L5 \\
\hline Protocols used & $\begin{array}{l}\text { Kovač Viršek et al., } 2015 \\
\text { Galgani et al., } 2013 \\
\text { Miller et al., } 2017 \\
\text { Van Cauwenberghe et } \\
\text { al., } 2015\end{array}$ & $\begin{array}{l}\text { Frias et al., } 2018 \\
\text { Kovač Viršek et } \\
\text { al., } 2015 \text { (SMP) }\end{array}$ & $\begin{array}{l}\text { Galgani et al., } \\
2013 \\
\text { Frias et al., } \\
2018 \\
\text { Kovač Viršek et } \\
\text { al., } 2015\end{array}$ & $\begin{array}{l}\text { Kovač Viršek et } \\
\text { al., } 2015\end{array}$ & $\begin{array}{l}\text { Frias et al., } 2018 \\
\text { Baini et al., } 2018\end{array}$ \\
\hline $\begin{array}{c}\text { Size of sieves/nets } \\
\text { used }\end{array}$ & $300 \mu \mathrm{m}, 1 \mathrm{~mm}, 5 \mathrm{~mm}$ & $1,6 \mu \mathrm{m}$ & $\begin{array}{c}300 \mu \mathrm{m}, 1 \mathrm{~mm}, \\
2 \mathrm{~mm}, 5 \mathrm{~mm}\end{array}$ & $\begin{array}{c}300 \mu \mathrm{m}, 1 \mathrm{~mm}, 5 \\
\mathrm{~mm}\end{array}$ & $200 \mu \mathrm{m}$ \\
\hline $\begin{array}{l}\text { Degradation of } \\
\text { biological material }\end{array}$ & / & $10 \% \mathrm{H}_{2} \mathrm{O}_{2}$ & / & / & / \\
\hline Density separation & Nal $[1.8 \mathrm{~g} / \mathrm{ml}]$ & $\mathrm{NaCl}\left[1.2 \mathrm{~g} / \mathrm{cm}^{3}\right]$ & $\begin{array}{l}\mathrm{NaCl}[1.2 \\
\left.\mathrm{g} / \mathrm{cm}^{3}\right]\end{array}$ & / & $\mathrm{NaCl}\left[1.2 \mathrm{~g} / \mathrm{cm}^{3}\right]$ \\
\hline $\begin{array}{l}\text { Chemical } \\
\text { identification of } \\
\text { particles }\end{array}$ & $\begin{array}{l}\text { ATR-FTIR for particles of } \\
\text { questionable } \\
\text { composition }\end{array}$ & / & / & $\begin{array}{l}\text { ATR-FTIR for } \\
\text { particles of } \\
\text { questionable } \\
\text { composition }\end{array}$ & $\begin{array}{l}\text { ATR-FTIR for } \\
\text { particles of } \\
\text { questionable } \\
\text { composition }\end{array}$ \\
\hline
\end{tabular}

\begin{tabular}{|c|c|c|c|c|c|}
\hline $\begin{array}{l}\text { Monitoring of } \\
\text { contamination* }\end{array}$ & Yes & Yes & No & Yes & Yes \\
\hline \multicolumn{6}{|l|}{ Water Samples } \\
\hline Laboratory & L1 & L2 & L3 & L4 & L5 \\
\hline Protocols used & Galgani et al., 2013 & $\begin{array}{l}\text { Kovač Viršek et } \\
\text { al., } 2016\end{array}$ & $\begin{array}{l}\text { Galgani et al., } \\
2013\end{array}$ & $\begin{array}{l}\text { Kovač Viršek et } \\
\text { al., } 2016\end{array}$ & $\begin{array}{l}\text { Baini et al., } 2018 \\
\text { Fossi et al., } 2017 \\
\text { Panti et al., } 2015 \\
\end{array}$ \\
\hline $\begin{array}{l}\text { Size of sieves/nets } \\
\text { used }\end{array}$ & $5 \mathrm{~mm}, 1 \mathrm{~mm}, 300 \mu \mathrm{m}$ & $250 \mu \mathrm{m}$ & $\begin{array}{c}300 \mu \mathrm{m}, 1 \mathrm{~mm}, \\
2 \mathrm{~mm}, 5 \mathrm{~mm}\end{array}$ & $\begin{array}{c}5 \mathrm{~mm}, 1 \mathrm{~mm}, \\
300 \mu \mathrm{m}\end{array}$ & $200 \mu \mathrm{m}$ \\
\hline $\begin{array}{l}\text { Degradation of } \\
\text { biological material }\end{array}$ & / & / & / & / & / \\
\hline $\begin{array}{l}\text { Chemical } \\
\text { identification of } \\
\text { particles }\end{array}$ & $\begin{array}{l}\text { ATR-FTIR for particles of } \\
\text { questionable } \\
\text { composition }\end{array}$ & & / & $\begin{array}{l}\text { ATR-FTIR for } \\
\text { particles of } \\
\text { questionable } \\
\text { composition }\end{array}$ & $\begin{array}{l}\text { ATR-FTIR for } \\
\text { particles of } \\
\text { questionable } \\
\text { composition }\end{array}$ \\
\hline
\end{tabular}

\section{Monitoring of} contamination* Yes

Yes

No

Yes

\section{Data processing}

The differences between the 'blind analysis' results and the reference values were calculated for every sample. The resulting error, in percentage, is given as the ratio of this difference to the reference value. The error can be positive in case of overestimation (analysis results $>$ reference value) or negative when underestimation (analysis results $<$ reference value).

In order to better understand and compare the sign and the degree of deviation when grouping the results per category (e.g. errors on film counts in sediment) average and root mean square errors (RMS) were used. The RMS error was calculated as follows:

$\mathrm{RMS}=\sqrt{\frac{\sum_{i=1}^{n}\left(y_{i}\right)^{2}}{n}}$

Where, $\mathrm{n}$ is the number of samples (sediment or water); $\mathrm{y}_{\mathrm{i}}$ is the reported error in \%. 
The RMS error was computed for total counts and total weight as well as for the counts of MP types (fragments, filaments, pellets, films, styrofoam) and colour categories included in the reference samples, provided by all laboratories in sediment and water samples separately. In addition, this process was repeated for the data provided by each participating laboratory separately.

\section{Post ICE analysis}

After collecting and processing the results from all laboratories during the 'blind analysis', and in order to understand better the exact reasons for deviations in counts in comparison to the reference values, a second stage of complementary analysis was carried out on 12 samples. This complementary, post ICE analysis included recounting of the MP particles extracted from the samples and additional polymer identification of selected particles. Three of the participating laboratories made chemical analysis of particles with ATR-FTIR spectrometers (Agilent Cary 630, Perkin Elmer Spectrum Two) mainly from samples where overestimation in total counts had occurred during the 'blind analysis'.

\section{3- Results}

\subsection{Total count and weight of MP}

A summary of the errors of the counts of particles and on the total weight of MP for both sediment and water samples is presented in Table 2. Regarding the total count of MP, the errors ranged from $24 \%$ to $+22 \%$ with the exception of one sample showing very high positive error ( $n^{\circ} 25$, error $+40 \%$ ). Overall, the results showed both under and over estimations with an error being under $25 \%$ in absolute value. A percentage of $60 \%$ of the errors were underestimation and $40 \%$ were overestimation.

For the total weight of MP, the errors ranged from $-25 \%$ to $+91 \%$. Only three out of 16 results had an error exceeding $25 \%$ in absolute value. Two of these results were overestimation (sample $n^{\circ} 25$, error $+91 \%$ and sample $n^{\circ} 28$, error $+46 \%$ ) and one was underestimation (sample $n^{\circ} 11$, error $-25 \%$ ). It should be noted that in some cases (e.g. samples $n^{\circ} 4$ and $n^{\circ} 20$ ) the sign of the error is opposite to the respective error on particles count. A percentage of $56 \%$ of the errors were underestimation and $44 \%$ were overestimation.

Table 2 : Summary of the differences (in \%) between the reference and the analysis results for the total count and weight of microplastics (MP). Details of errors by type of particles can be found in Supplementary material (Table S3)

\begin{tabular}{|c|c|c|c|c|c|c|c|}
\hline $\begin{array}{c}\text { Type of sample and } \\
\text { concentration range of MP }\end{array}$ & Sample $n^{\circ}$ & $\begin{array}{c}\text { Total count of } \\
\text { MP } \\
\text { (reference) }\end{array}$ & $\begin{array}{l}\text { Total count of } \\
\text { MP (analysis) }\end{array}$ & $\begin{array}{l}\text { Error total } \\
\text { count (\%) }\end{array}$ & $\begin{array}{l}\text { Total weight of } \\
\text { MP in grams } \\
\text { (analysis) }\end{array}$ & $\begin{array}{l}\text { Error total } \\
\text { weight of MP } \\
\text { (\%) }\end{array}$ & Lab. \\
\hline \multicolumn{8}{|l|}{ Sediment } \\
\hline \multirow{6}{*}{ High concentration } & 3 & 146 & 121 & -17 & nd* & nd* & L2 \\
\hline & 4 & 134 & 131 & -2 & 0.42918 & 7 & L5 \\
\hline & 6 & 143 & 163 & 14 & 0.52684 & 23 & L1 \\
\hline & 7 & 136 & 123 & -10 & $\mathrm{nd}^{*}$ & & L2 \\
\hline & 8 & 136 & 123 & $-10^{\#}$ & 0.3462 & -7 & L4 \\
\hline & 11 & 142 & 119 & -16 & 0.2795 & -25 & L3 \\
\hline
\end{tabular}




\begin{tabular}{|c|c|c|c|c|c|c|c|}
\hline & 20 & 75 & 84 & 12 & 0.2088 & -5 & L3 \\
\hline \multirow{4}{*}{ Low concentration } & 24 & 77 & 80 & 4 & 0.21711 & 10 & L5 \\
\hline & & & & & & & \\
\hline & 25 & 81 & 113 & 40 & 0.30308 & 91 & L1 \\
\hline & 28 & 81 & 63 & $-22^{\#}$ & 0.1653 & 46 & L4 \\
\hline \multicolumn{8}{|l|}{ Water } \\
\hline \multirow{5}{*}{ Low concentration } & 31 & 89 & 75 & -16 & 0.2103 & -4 & L3 \\
\hline & 32 & 91 & 69 & -24 & nd* & & $\mathrm{L} 2$ \\
\hline & 36 & 83 & 101 & 22 & 0.20577 & 4 & L1 \\
\hline & 39 & 89 & 78 & -12 & 0.1928 & -6 & L4 \\
\hline & 40 & 97 & 96 & -1 & 0.21501 & $-0,2$ & L5 \\
\hline \multirow{5}{*}{ High concentration } & 44 & 149 & 143 & -4 & 0.2716 & -6 & L3 \\
\hline & 45 & 160 & 161 & 1 & 0.31636 & -4 & L1 \\
\hline & 47 & 162 & 167 & 3 & 0.35615 & 1,5 & L5 \\
\hline & 49 & 158 & 125 & -21 & nd* & $\mathrm{nd}^{*}$ & $\mathrm{~L} 2$ \\
\hline & 50 & 149 & 151 & 1 & 0.3536 & -10 & L4 \\
\hline
\end{tabular}

* nd corresponds to no data

\# the first counts of filaments in samples 8 and 28 were approximately 10 -fold above the reference due to a contamination by a laboratory equipment when processing the samples. These initial filament counts have been considered as outliers for the rest of the study. The number then used is computed excluding filament counts.

\section{Analysis performance per sample matrix}

Figure 1 shows RMS and average values of errors which have been computed according to total count, total weight and particle types for both sample matrices. In general, the error in total particle count was slightly greater for sediment samples (RMS 18\%) than for water samples (RMS 14\%). The average error is negative both for sediment $(-1 \%)$ and water $(-5 \%)$ but the error pattern differs if considering the total weight of MP particles. The error is then much higher for sediment (RMS 44\%) than water (RMS 6\%). In sediment samples the average error (16\%) is positive while it is negative (4\%) for water. 


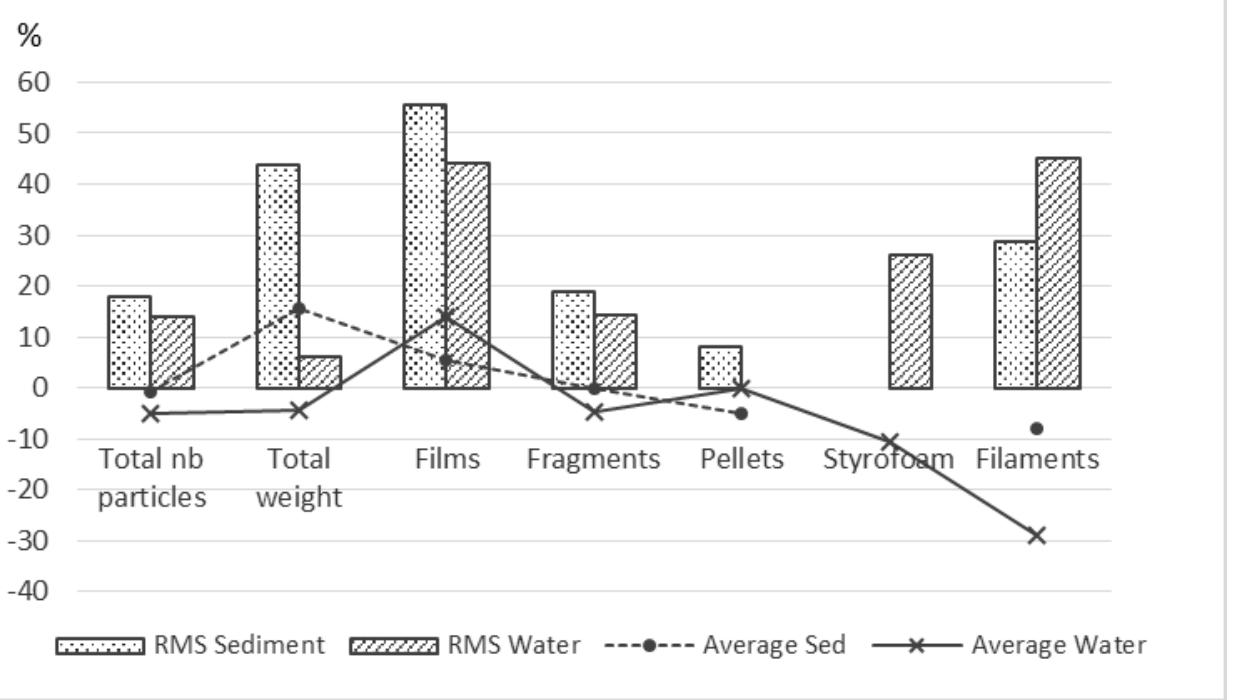

Figure 1 : RMS and average errors (\%) of MP total count and total weight as well as MP categories in sediment and water samples. Note: no styrofoam particle was added when preparing the sediment reference samples.

\section{Analysis performance per laboratory}

When comparing counts on MP by matrix and laboratory, notable differences are seen among laboratories (Figure 2). The most prominent features are the small errors from L5 (RMS 3\% in sediment and $2 \%$ in water) and the errors above $20 \%$ for sediment samples analysed by L1 (30\%) and water samples by L2 (23\%). The other RMS values are in the range $9-17 \%$.

It is also noticeable that in case of $L 1$, the average error is positive whereas that for $L 2, L 3$ and $L 4$ is negative.

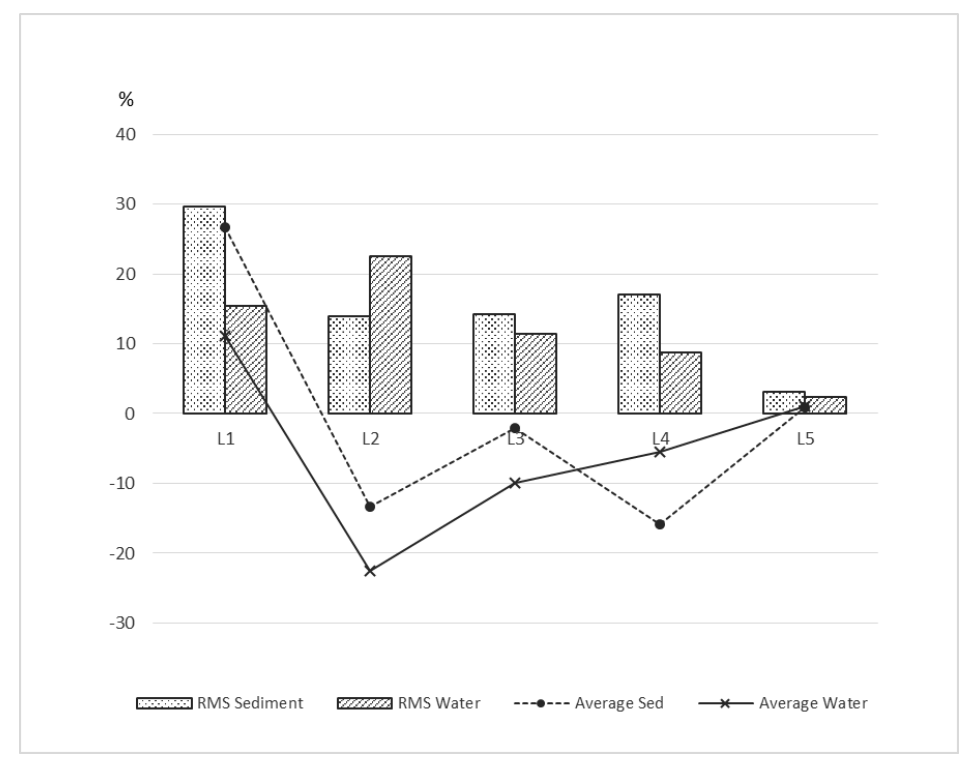

Figure 2 : Average and RMS errors (\%) of total counts of MP in sediment and water reference samples per laboratory

\subsection{Counts of MP per type}


The errors of the MP type analysis (Table S3, Suppl. Material) range from $-84 \%$ to $+110 \%$. Both these extreme values are observed for the films category. If the data are grouped by matrix (Figure 1), then the errors are: for pellets RMS $8 \%$ in sediment, no error in water; for fragments RMS $19 \%$ in sediment and $14 \%$ in water; for styrofoam RMS $26 \%$ in water; for filaments $29 \%$ in sediment and $45 \%$ in water; and for films RMS $56 \%$ in sediment and $44 \%$ in water.

It appears also that the sign of the average error is different depending on the type of MP. On average, films' counts are overestimated ( $5 \%$ sediment, $14 \%$ water), while for nearly all other types, average errors are zero or negative: fragments ( $0 \%$ sediment, $-5 \%$ water), pellets ( $-5 \%$ sediment, $0 \%$ water), styrofoam (-11\% in water) and filaments (-8\% in sediment and $-29 \%$ in water).

\subsection{Colour of MP}

The particles introduced into the samples were classified into four out of the eight colour categories: blue, orange/pink/red, transparent and white. Table 3 summarizes the differences in count of particles between the 'blind analysis' and the reference values for these four colour classes. The erroneous counts of particles of other EMODnet colour classes (black, brown, yellow and opaque) are also given.

Table 3: Summary of the differences (errors in \%) between the reference and the analysis results for the colour of the microplastic particles

\begin{tabular}{|c|c|c|c|c|c|c|c|c|c|c|}
\hline & Sample $\mathrm{n}^{\circ}$ & $\begin{array}{l}\text { Error } \\
\text { blue \% }\end{array}$ & $\begin{array}{l}\text { Error orange/ } \\
\text { pink/red \% }\end{array}$ & $\begin{array}{c}\text { Error transparent } \\
\%\end{array}$ & $\begin{array}{c}\text { Error } \\
\text { white \% }\end{array}$ & Black & Brown & Yellow & Opaque & Lab. \\
\hline \multirow[t]{2}{*}{ Sediment } & & & & & \multicolumn{6}{|c|}{$\begin{array}{l}\text { Count of particles of colour not registered in } \\
\text { the reference }\end{array}$} \\
\hline & 3 & 40 & 4 & -38 & -48 & 3 & 0 & 0 & 14 & $\mathrm{~L} 2$ \\
\hline \multirow{5}{*}{ 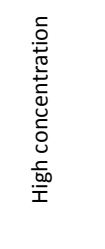 } & 4 & 22 & 0 & 15 & -32 & 0 & 0 & 0 & 2 & L5 \\
\hline & 6 & 125 & 14 & -15 & -23 & 3 & 0 & 5 & 9 & L1 \\
\hline & 7 & 88 & 8 & -37 & -42 & 0 & 0 & 0 & 19 & L2 \\
\hline & 8 & 14 & -18 & -47 & -41 & 0 & 0 & 1 & 36 & L4 \\
\hline & 11 & 7 & -18 & 3 & -49 & 0 & 0 & 0 & 0 & L3 \\
\hline \multirow{4}{*}{ 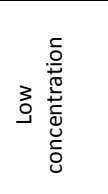 } & 20 & 30 & -33 & 21 & 0 & 0 & 0 & 1 & 0 & L3 \\
\hline & 24 & 13 & 0 & 15 & -24 & 0 & 0 & 0 & 0 & L5 \\
\hline & 25 & 178 & 55 & 0 & 10 & 1 & 0 & 2 & 5 & L1 \\
\hline & 28 & -18 & 0 & -52 & -50 & 0 & 0 & 0 & 15 & L4 \\
\hline \multicolumn{11}{|l|}{ Water } \\
\hline \multirow{5}{*}{ 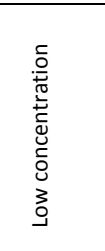 } & 31 & 0 & -30 & -18 & -33 & 0 & 0 & 0 & 7 & L3 \\
\hline & 32 & 10 & 20 & -55 & -39 & 0 & 0 & 0 & 9 & L2 \\
\hline & 36 & 42 & 263 & -61 & 15 & 4 & 0 & 0 & 6 & L1 \\
\hline & 39 & 44 & 22 & -33 & -41 & 2 & 0 & 1 & 6 & L4 \\
\hline & 40 & 10 & 15 & -36 & -34 & 0 & 0 & 0 & 22 & L5 \\
\hline \multirow{5}{*}{ 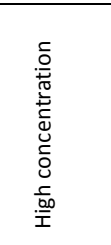 } & 44 & 0 & -45 & -4 & -13 & 0 & 0 & 0 & 13 & L3 \\
\hline & 45 & 20 & -4 & 19 & -34 & 0 & 0 & 1 & 5 & L1 \\
\hline & 47 & 11 & 0 & -29 & -27 & 0 & 0 & 0 & 41 & L5 \\
\hline & 49 & 0 & -9 & -31 & -41 & 0 & 0 & 0 & 14 & L2 \\
\hline & 50 & 57 & -5 & 18 & -45 & 5 & 0 & 0 & 4 & L4 \\
\hline
\end{tabular}

The error on colour ranges from $-61 \%$ to $+263 \%$. Pooling errors by matrix for the 4 colour classes (Figure 3 ) shows that the errors are on average greater for the classification of particles by colour 
than by type (Figure 1). For the four colour categories, RMS errors always exceed $20 \%$ and large differences in errors depending on matrix and colour class were observed (Figure 3 ).

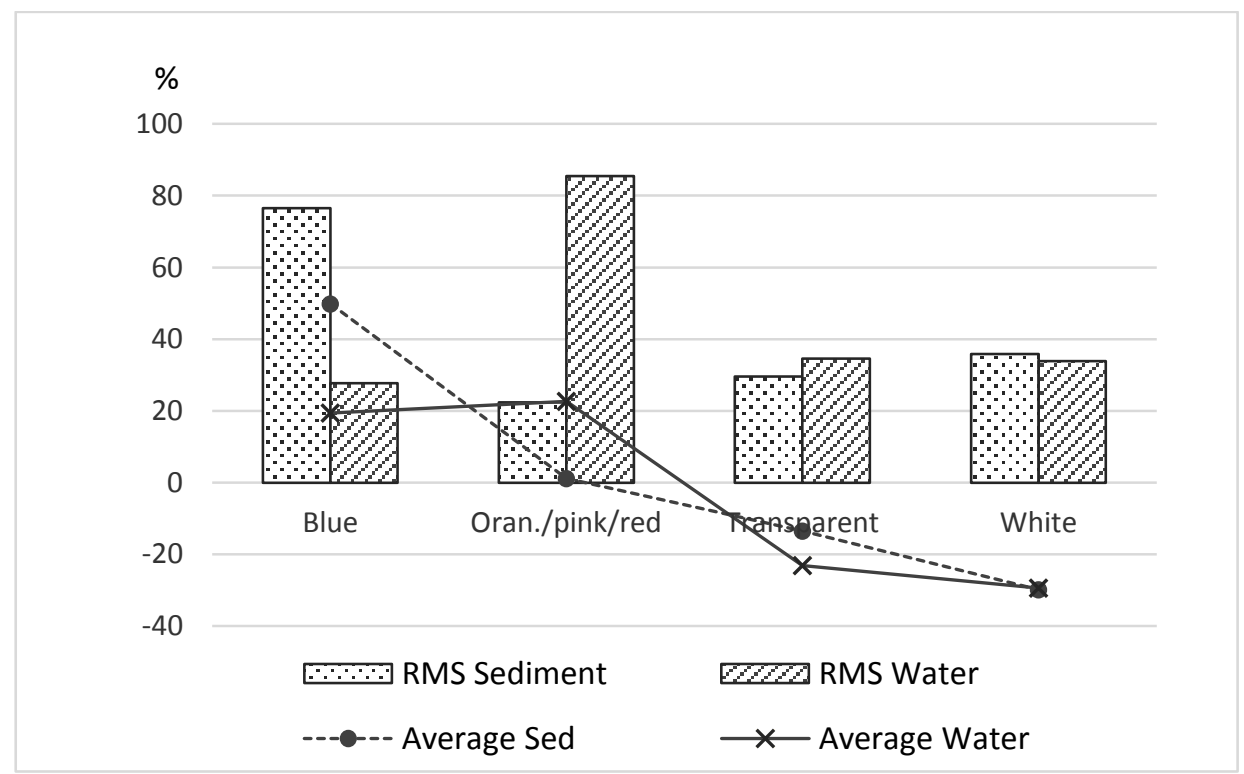

Figure 3: Difference in colour of microplastic particles in comparison to the reference in \% and RMS errors in sediment and water samples

- According to blue category, the RMS values show that errors are lower in water (28\%) than in sediment (77\%). Overestimation is by far the most frequent error, being the average error values $+19 \%$ in water and $+50 \%$ in sediment with only one analysis (sample $n^{\circ} 28$ ) giving a negative error.

- Orange/Pink/Red category: RMS values are higher in water (85\%) that in sediment (22\%). Average errors are $+23 \%$ in water and $+1 \%$ in sediment. However, in water the error on sample $n^{\circ} 36(+263 \%)$ is the only one above $45 \%$ in absolute value. This large error conditions the high value of the RMS.

- Transparent category: RMS errors are similar for water (35\%) and sediment (30\%). In both cases, underestimation dominates with average error $-23 \%$ in water and $-13 \%$ in sediment.

- White category: it shows a similar pattern with no obvious differences between water (RMS 34\%) and sediment (36\%). All analytical results except two show an underestimation. Average errors are $29 \%$ in water and $-30 \%$ in sediment.

On average, the total numbers of particles counted in other colour classes, in relation to the total number of particles counted in the analysis, are $10 \%$ in sediment and $12 \%$ in water samples. Most of these particles were classified in the opaque category (average $74 \%$ in sediment and $85 \%$ in water). No particle were classified as brown and very few as yellow and black.

\subsection{Post-ICE analysis}

Additional FTIR analysis was carried out for all the samples except $n^{\circ} 3,7,32$ and 49 . By providing information on the material of each particle, FTIR results allowed to detect particles incorrectly identified as polymers (e.g. mineral) and MP made of polymers different from those used as parent material during the preparation of the samples (Table 4). Figure 4 shows an example of films identified made of polyethylene, not originally included in the reference samples. 
Figure 4: Example of white film (top) identified as polyethylene (PE) by the similarity of its spectral absorbance with a reference polymer (bottom)

Table 4: Results of the FT-IR analysis carried out on the particles extracted from the samples and counted as MP

\begin{tabular}{|c|c|c|}
\hline & Sample $n^{\circ}$ & Information given by FT-IR analysis \\
\hline \multirow{11}{*}{ Sediment } & 4 & All counted particles confirmed as MP \\
\hline & & $\begin{array}{l}7 \text { films made of other polymer than the one used for } \\
\text { preparing the samples }\end{array}$ \\
\hline & 6 & 3 films identified as natural organic material \\
\hline & & $\begin{array}{l}4 \text { fragments of other plastic than those used for the } \\
\text { exercise }\end{array}$ \\
\hline & 8 & All counted particles confirmed as MP \\
\hline & 11 & $\begin{array}{l}4 \text { fragments identified as stone or glass } \\
1 \text { styrofoam identified as other plastic }\end{array}$ \\
\hline & 20 & $\begin{array}{l}2 \text { fragments identified as other plastic } \\
2 \text { items identified as organic material }\end{array}$ \\
\hline & 24 & All counted particles confirmed as MP \\
\hline & & 4 films identified as other plastic \\
\hline & 25 & $\begin{array}{l}9 \text { fragments identified as other plastic } \\
15 \text { fragments identified as mineral }\end{array}$ \\
\hline & 28 & 3 particles identified as mineral \\
\hline \multirow{7}{*}{ Water } & 36 & All counted particles confirmed as MP \\
\hline & 39 & All counted particles confirmed as MP \\
\hline & 40 & All counted particles confirmed as MP \\
\hline & 44 & Count of 8 styrofoam particles confirmed \\
\hline & 45 & 1 fragment identified as a stone \\
\hline & 47 & All counted particles confirmed as MP \\
\hline & 50 & 1 particle identified as non-plastic \\
\hline
\end{tabular}

For 12 samples, plastics particles were recounted. In some cases, the recounting was not done on all types of particles (see Table 5). The recounting was performed by one or two operators of the same laboratory (for 8 samples) and of a different laboratory (for 4 samples). In case of two operators, the number provided for the recount resulted from an agreement by both operators. Table 5 shows the results of the various counts obtained for the samples which have been recounted and informs on the laboratory which did the recounting. The second count takes into account the information 
provided by FTIR analysis. It is therefore more reliable as regards to the nature of the items detected (polymers or not).

Table 5 : Total number of microplastic particles found in the samples that have been recounted

\begin{tabular}{|c|c|c|c|c|c|c|c|c|c|}
\hline & & & & st cour & & & nd $\operatorname{cou}$ & & \\
\hline & $\begin{array}{c}\text { Sample } \\
\mathrm{n}^{\circ}\end{array}$ & $\begin{array}{l}\text { Num. MP } \\
\text { reference }\end{array}$ & Total & Lab & $\begin{array}{c}\text { Error } \\
(\%)\end{array}$ & Total & Lab & $\begin{array}{c}\text { Error } \\
(\%)\end{array}$ & Comments \\
\hline \multirow{6}{*}{ Sediment } & 6 & 143 & 163 & L1 & +14 & 153 & L1 & +7 & \multirow{5}{*}{ Recounts of films only } \\
\hline & 8 & 136 & 123 & L4 & -10 & 126 & L4 & -7 & \\
\hline & 11 & 142 & 119 & L3 & -16 & 109 & L1 & -23 & \\
\hline & 20 & 75 & 84 & L3 & +12 & 74 & L1 & -1 & \\
\hline & 25 & 81 & 113 & L1 & +40 & 96 & L1 & +19 & \\
\hline & 28 & 81 & 63 & L4 & -22 & 70 & L4 & -14 & Filaments excluded \\
\hline \multirow{6}{*}{ Water } & 31 & 89 & 75 & L3 & -16 & 67 & L1 & -25 & \multirow{5}{*}{$\begin{array}{l}\text { Filaments not } \\
\text { recounted }\end{array}$} \\
\hline & 36 & 83 & 101 & L1 & +22 & 90 & L1 & +8 & \\
\hline & 39 & 89 & 78 & L4 & -12 & 77 & L4 & -13 & \\
\hline & 44 & 149 & 143 & L3 & -4 & 128 & L1 & -14 & \\
\hline & 45 & 160 & 161 & L1 & +1 & 160 & L1 & 0 & \\
\hline & 50 & 149 & 151 & L4 & +1 & 144 & L4 & -10 & $\begin{array}{l}\text { Recounts of } \\
\text { fragments only }\end{array}$ \\
\hline
\end{tabular}

In almost all cases (10 samples out of 12), the recount results in a lower number than in the first count. In only one case, the recounting found a higher number of MP. The calculation of the RMS values gives, for the $1^{\text {st }}$ and $2^{\text {nd }}$ counts $22 \%$ and $14 \%$ for sediment samples and $12 \%$ and $14 \%$ for water samples, respectively. Overall, the recounting lead to an improvement of the results for sediment samples but not for water samples.

\section{4 - Discussion}

In this section, after listing the possible reasons which can explain these errors, the detailed discussion will focus on the total counts, the types of particles, the colours and finally the methodologies applied by the laboratories.

The different analytical methods performed by the laboratories and the different operators have given results that either are underestimating or overestimating the counting of MP. These differences have been presented according to the matrix, categories or colours of particles in Tables 2 and 3.

In case of overestimation, the potential sources of bias could be due to:

- Incomplete cleaning of the matrix material used for the preparation of reference samples

- Contamination of the sample by MP during the processing/analysis phase

- Fragmentation of microparticles

- Misidentification, i.e. identification of a non-plastic particle (e.g. a piece of mussel shell) as plastic

- Miscategorisation

- Miscounting

In case of understimation, the potential sources of bias could be from:

- Loss of the particles during processing 
- Miscounting

- Misidentification, e.g. identification of film-type MP as dead plant material

- Miscategorisation

Unless other error factors, miscategorisation doesn't have an influence on total number of particles in the sample.

\section{Total count of microplastic particles}

According to Table 2, overestimation is encountered in 8 out of 20 samples, where three of them are water samples with an error in the range 1-3\%. For these three samples ( $n^{\circ} 45,47$ and 50 ), except in the case of sample $n^{\circ} 50$ in which one particle was detected as non-plastic by FT-IR analysis, the most probable explanation of the errors is fragmentation of original particles. The same assumption is made for sediment sample $n^{\circ} 24$ (error $+4 \%$, i.e. three particles). This is supported by the similarity observed between the particles extracted from the sample and the original MP as pointed out by post stereoscopic analysis.

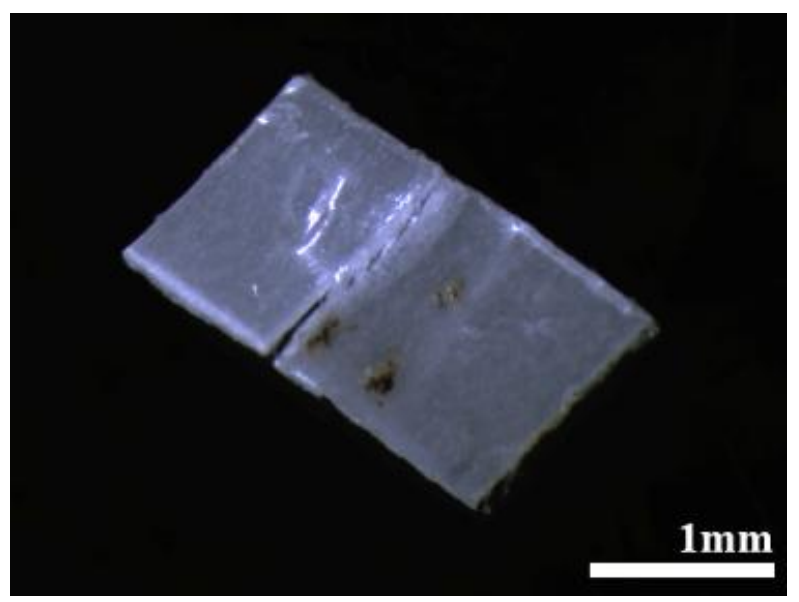

Figure 5 : Example of a particle in the process of fragmentation found in an ICE sample

For sediment sample $\mathrm{n}^{\circ} \mathbf{2 0}$, it is more difficult to conclude on the reason of the error. Post FT-IR analysis showed that two particles initially counted as MP were actually organic material and two were made of other plastic than the ones used in the exercise. The error can then be attributed to misidentification or probably, could be due to contamination or to the presence of few plastic particles in the sediment originally used for preparing the samples. The characteristics of the particles allow to support this later hypothesis rather than that of a posteriori contamination. Thus, it is possible that the sediment used for the exercise was not totally cleaned from micro plastics before adding the known ones. Meanwhile, the second counting resulted in a slight underestimation $(-1 \%)$, suggesting a possible miscounting at the first stage.

The three remaining overestimated samples $\left(n^{\circ} 6,25\right.$ and 36$)$ have been analysed by the same laboratory. In this case the error is relatively high (respectively 14, 40 and $22 \%$ ). In these three cases, the recounting gave an error notably lower than in the first counting. For water sample $n^{\circ} 36$, the difference between both counts is probably due to miscounting at the first stage. The appearance and shape of the plastic particles show similarities with the MP originally introduced in the reference sample. This supports the hypothesis of fragmentation of the particles (e.g. during transportation, sieving or laboratory procedures) for explaining the remaining part of the error. For sediment samples $n^{\circ} 6$ and 25, FT-IR analysis demonstrates that a large part of the error is due to the presence of films and fragments made of other plastic than the ones put in the reference samples. The dirty and aged look of films and the shape of fragments suggest that these items pre-existed in the 
sediment and were not removed during the cleaning phase. Misidentification (natural organic particles for $n^{\circ} 6$ and mineral ones for $n^{\circ} 25$ ) is the other main reason of error. For sample $n^{\circ} 25$ miscounting at the first stage is also probable.

Several hypotheses can be put forward to explain the negative error of the remaining 12 samples. The suspected causes of underestimation are of different kinds: non detection by the operator, particle stuck to a container or filter, particle lost or blown by an air stream during handling. Miscounting is also possible. This has been proved for samples $n^{\circ} 8$ and 28 (L4) for which the second counting gave higher number than the first one reducing errors to respectively $-7 \%$ and $-14 \%$.

Among these 12 underestimated counts, it can be observed that:

- two of them (samples $n^{\circ} 4$ and 40 analysed by L5) show a very small error (-2 and $\left.-1 \%\right)$ which can be considered as insignificant

- three samples $\left(n^{\circ} 11,31,44\right)$ were recounted by different operators from different laboratories ( $\mathrm{L} 3$ then L1). A loss of particle between both counts is probable.

- For several results, missing particles are mainly from one 1 or 2 types:

$\circ \quad \mathrm{N}^{\circ} 3$ and 7 (sediment, L2): error is mainly due to a lack of films

- $\quad \mathrm{N}^{\circ} 32$ and 49 (water, L2): the error concentrates on styrofoam and filaments

- $\quad N^{\circ} 39$ (water, L4): missing particles are mainly styrofoam and filaments

- $\quad \mathrm{N}^{\circ} 31$ (water, L3): underestimation is mainly on films and filaments

- $\mathrm{N}^{\circ} 44$ (water, L3): underestimation is mainly on films

Especially if it regards the same laboratory, the different error patterns observed (e.g. sediment vs water for L2) suggest that the cause of the underestimation is a loss of particles during the analytical process rather than miscounting. For the samples analysed by $L 2$, which was the only laboratory pretreating sediment samples with $\mathrm{H}_{2} \mathrm{O}_{2}$ before the density separation, the underestimation could be related to the use of this chemical compound that can degrade plastics such as films (Prata et al., 2019b).

A summary of the most likely cause of errors on total counts of MP is presented in Table 6.

Table 6 : Hypotheses on the reasons of errors on total count of microplastics

\begin{tabular}{|c|c|c|c|c|}
\hline & $\begin{array}{c}\text { Sample } \\
n^{\circ}\end{array}$ & Laboratory & $\begin{array}{l}\text { Error on } \\
\text { total count }\end{array}$ & Most likely reasons of error \\
\hline \multirow{10}{*}{ Sediment } & 3 & L2 & $-17 \%$ & Loss of particles and/or miscounting \\
\hline & 4 & L5 & $-2 \%$ & Loss of particles \\
\hline & 6 & L1 & $14 \%$ & Incomplete cleaning of sediment, misidentification \\
\hline & 7 & L2 & $-10 \%$ & Loss of particles \\
\hline & 8 & L4 & $-6 \%$ & Miscounting (and contamination by filaments during drying) \\
\hline & 11 & L3 & $-16 \%$ & Loss of particles + contamination ( 1 styrofoam) \\
\hline & 20 & L3 & $12 \%$ & Incomplete cleaning of sediment, misidentification \\
\hline & 24 & L5 & $4 \%$ & Fragmentation \\
\hline & 25 & L1 & $40 \%$ & Incomplete cleaning of sediment, misidentification, miscounting \\
\hline & 28 & L4 & $-11 \%$ & Miscounting (and contamination by filaments during drying) \\
\hline \multirow{6}{*}{ Water } & 31 & L3 & $-16 \%$ & Loss of particles \\
\hline & 32 & L2 & $-24 \%$ & Loss of particles \\
\hline & 36 & L1 & $22 \%$ & Miscounting, fragmentation \\
\hline & 39 & L4 & $-12 \%$ & Loss of particles \\
\hline & 40 & L5 & $-1 \%$ & Loss of particles \\
\hline & 44 & L3 & $-4 \%$ & Loss of particles \\
\hline
\end{tabular}


The small errors obtained by L5 would tend to show a superiority of the protocol used for both sediment and water samples. However, the methodology used by this laboratory is similar to the one used by L2, L3 and L4. A notable difference is that this laboratory has coded each particle separately when storing them in petri dishes. Precautions taken during handling and the experience of the operators seem also to be factors that can explain the quality of the results.

The use of $\mathrm{Nal}$ instead of $\mathrm{NaCl}$ for density separation in sediment samples is a factor that can explain a part of the overestimation in L1 (Miller et al., 2017). As the cleaning of the sediment of reference samples was done using $\mathrm{NaCl}\left[1.2 \mathrm{~g} / \mathrm{cm}^{3}\right]$ for density separation, it may have led to missing some MP. These particles would then have been revealed by a more dense flotation solution Nal $\left[1.8 \mathrm{~g} / \mathrm{cm}^{3}\right]$. Also misidentification has caused overestimation in the analyses of L1.

For the three laboratories whose results are generally underestimated (L2, L3 and L4), particle loss or non-detection appears to be the most likely reason, with counting errors in some cases.

\section{Types of microplastic particles}

Several hypotheses can be put forward to explain the significant differences of errors between the types of particles identified during the ICE.

Given their relative large size and regular shape, the pellets are easier to identify and therefore less prone to error. For this type, only four sediment samples $\left(n^{\circ} 3,6,7,11\right)$ have an error (1 out of 8 missing pellets).

Styrofoam was included only in reference water samples. Accordingly, no styrofoam particles have been found in sediment except in one sample analysed by $L 3$ (one microparticle). Water sample $n^{\circ} 44$ (L3) shows an overestimation of styrofoam particles. This is probably due to contamination or fragmentation of the particles initially present during the sample processing. An underestimation of styrofoam MP is observed in 4 water samples $\left(n^{\circ} 32,39,45,49\right)$. It is supposed that a loss of material occurred during the analytical process, which can be favoured by the lightness of the styrofoam pieces in comparison to other types of plastics.

For filaments, negative errors clearly dominate especially in water samples. This may be due to the fact that the added items were transparent. There are also differences from one laboratory to another. The highest underestimation comes from L2 in the water samples (average -80\%). These underestimations are supposed to be the consequence of the loss of material that can result for example from particles trapped in the deposit with biological material or lost at the filtering stage. Additionally, it should be noted that the lower errors on filaments have been obtained by $L 5$ which used only one filtering step with a $200 \mu \mathrm{m}$ sieve, limiting therefore the risk of missing filaments because remaining stuck on the filter.

In average, error on fragments is the lowest after pellets. The most important positive errors (samples $n^{\circ} 20,25,36$ ) have been explained in the previous paragraphs. If the most significant negative error $(<-10 \%)$ is considered, it is possible to separate: on the one hand samples $n^{\circ} 4,24,40$ and 47 analysed by $L 5$ for which the missing number of fragments is nearly the same as the number 
of exceeding films in the same sample, suggesting a miscategorisation, and on the other hand, samples $n^{\circ} 11$ (L3), 32 and 49 (L2) for which this transfer among categories is not seen, leading to the assumption of a loss of particles or a non detection.

For films, the results differ greatly from one laboratory to another. It appears that the errors are generally of the same order for the two samples of the same matrix analysed by each laboratory. The significant overestimation of films in sample $n^{\circ} 6$ has been already discussed above, when considering total counts. Regarding underestimations, significant errors are found in samples analysed by L2 (-82 and $-84 \%$ for sediment $n^{\circ} 3$ and 7 , respectively) and $L 3\left(-22,-25\right.$ and $-40 \%$ for $n^{\circ} 11,31$ and 44 , respectively). As these errors cannot be attributed to a miscategorisation, they are probably due to a non-detection or loss of particles resulting from the weaknesses of the method used.

\section{Colour}

On most of the samples, including samples with a very low error on total counts of particles, a common pattern is observed, with negative values of error for white and transparent and positive values of error for blue and orange/pink/red. The most probable hypothesis is a miscategorisation. This can result either from the difficulty to choose among classes for a particle (e.g. white and opaque) or from an alteration of the original colour of the particle while processing the sample. This latter assumption is particularly relevant for laboratory (L1) that has used Nal as a flotation media during preprocessing of sediment samples.

The increased errors in colour classification can also be explained by factors such as the light conditions in the laboratory and the colour perception of the operators.

Based on the results of the present ICE, it appears that the information on the colour of the particles is least trustful. Taking into account also that the colour of a plastic particle can change over time, especially in natural environments, due to its exposure to light and mechanical weathering, we suggest to reconsider the list of colour categories in the EMODnet classification. Apart from the fact that the colour of the particles can influence their rate of ingestion by animals as they are mistaken for their usual food, the interest for the information of colour is not obvious.

\section{5 - Conclusions and recommendations}

Underestimation is the most frequent cause of error. In the targeted particle classes, the risk of nondetection (human error) and loss of particles appears to be greater than the risk of contamination. This assertion is reinforced by the fact that the recounting of the particles did not give consistent results. This is in accordance with the conclusion of Isobe et al, (2019) who point that an increase of handling might result in a risk of loss of MP.

The relatively small errors on total counts of MP obtained on the four samples analysed by L5 demonstrates the validity of protocols used by this laboratory for the kind of samples prepared for the ICE, i.e. samples with a low concentration of organic material. The main characteristics of the protocols applied by $\mathrm{L} 5$ were for sediment samples: $\mathrm{NaCl}\left[1.2 \mathrm{~g} / \mathrm{cm}^{3}\right]$ density separation, one filtering step $(200 \mu \mathrm{m})$, no $\mathrm{H}_{2} \mathrm{O}_{2}$ or $\mathrm{KOH}$ degradation of organic material; and for water samples: one filtering step $(200 \mu \mathrm{m})$. Precautions taken in this laboratory and the operators' experience must also have contributed to the quality of these results.

The difficulty to get clean natural sediment reference material is an issue. Thorough cleaning of the sediment used for the intercalibration exercise is necessary prior to the exercise, to avoid contamination leading to positive errors. The availability of such clean reference material should be ensured in order to facilitate the assessment of the performance of laboratories. 
The step of the post analysis of the ICE has demonstrated the usefulness of FT-IR analysis in removing ambiguities on some mineral and biological particles that can be easily mistaken as plastic, especially in sediment samples. By identifying the polymer, FT-IR analysis gives also information that can help to know the origin of the particles and the possible source of pollution. However, in the MSFD monitoring programmes, the high cost of such analyses can be a barrier to their widespread use. For this reason, other analytical techniques, for example fluorochrome analysis, need to be further explored and compared to FT-IR in terms of cost/performance ratio.

Regarding the categories of particles, the greatest errors are seen on films and filaments. On the one hand, the distinction between films and fragments is not always obvious especially when particles are flat; while on the other hand, the detection of filament shaped MP, seems to be more difficult than of other particles, especially when filaments are transparent as in the case of the present ICE.

Regarding the colour of MP, it appears difficult to obtain reliable and comparable data due to several factors, in particular alteration during sample processing and subjectivity of the operators. The relevance of this information on the colour of the MP is therefore not obvious. Given the high risk of miscategorisation and the relatively low interest in the MP colour information (compared to the type or the polymer of the particle), it is suggested to reduce the number of colour classes to five: dark (black, brown, dark grey), blue/green, pale (white, cream, yellow), orange/pink/red and transparent

As analyses require a lot of manipulation and operations involving a human operator, the experience and know-how of the staff involved seem to have a significant impact on the quality of the results. Attention should therefore be paid to the training of operators. It should be pointed that analysis of water samples is easier than of sediments. Sediment samples require a pre-treatment including a density separation, whereas for the water samples, the method is more direct, with less manipulation of the "raw" sample. However, the high variability of MP concentrations observed in surface waters often makes it difficult to interpret analyses of water samples taken at sea. Due to the integrating nature of the sediments, the analysis of MP in this matrix remains very relevant and the improvement of the analytical methods must remain a priority.

In conclusion, this first intercalibration exercise performed among different laboratories at European level highlighted the difficulty of obtaining comparable results on similar samples. This is a weakness which makes difficult a sound assessment of plastic pollution at regional scale. The harmonization of MP monitoring methods for all environmental compartments, including biota and the introduction of standards ensuring the accuracy of the analysis and the robustness of the results should therefore be a priority. 
Acknowledgements

We thank the technicians who participated in the sample preparation and analysis Fabienne Chavanon, Maryvonne Henry, Danielle Louedoc, Françoise Marco-Miralles, Christophe Ravel, Benoist de Vogüé. We also thank M. Compa for assistance at the laboratory of the Spanish Institute of Oceanography, Balearic Centre of Oceanography.

This work has been carried out within the frame of MEDCIS European project (grant agreement $\mathrm{n}^{\circ}$ 11.0661/2016/748067/SUB/ENV.C2-MEDCIS).

\section{References}

Alimba, C.G. and Faggio, C., 2019. Microplastics in the marine environment: Current trends in environmental pollution and mechanisms of toxicological profile. Environmental Toxicology and Pharmacology 68, 61-74.

Alomar, C., Deudero S. 2017. Evidence of microplastic ingestion in the shark Galeus melastomus Rafinesque, 1810 in the continental shelf off the western Mediterranean Sea. Environmental Pollution, 223, 223-229.

Arthur, C., Baker, J.E., Bamford, H., 2009. Proceedings of the International Research Workshop on the Occurrence, Effects, and Fate of Microplastic Marine Debris, September 9-11, 2008, University of Washington Tacoma, Tacoma, WA, USA -:2509 | National Ocean Service (NOS)." 2009. https://repository.library.noaa.gov/view/noaa/2509.

Baini, M., Fossi, M.C., Galli, M., Caliani, I., Campani, T., Finoia, M.G., Panti, C. (2018). Abundance and characterization of microplastics in the coastal waters of Tuscany (Italy): The application of the MSFD monitoring protocol in the Mediterranean Sea. Marine Pollution Bulletin 133, 543-552. https://doi.org/10.1016/j.marpolbul.2018.06.016.

Barboza, L., Gimenez, B., 2015. Microplastics in the marine environment: Current trends and future perspectives. Marine Pollution Bulletin 97, 5-12.

Caruso, G., 2019. Microplastics as vectors of contaminants. Mar Pollut Bull 146, 921-924.

Cincinelli, A., Martellini, T., Guerranti, C., Scopetani, C., Chelazzi, D., Giarrizzo, T., 2019. A potpourri of microplastics in the sea surface and water column of the Mediterranean Sea. TrAC Trends in Analytical Chemistry 110, 321-326.

Crise A. et al., (2015). A MSFD complementary approach for the assessment of pressures, knowledge and data gaps in Southern European Seas: The PERSEUS experience. Marine Pollution Bulletin, 95(1), 28-39.

Darmon, G., Miaud, C., Claro, F., Doremus, G., Galgani, F., 2017. Risk assessment reveals high exposure of sea turtles to marine debris in French Mediterranean and metropolitan Atlantic waters. Deep Sea Research Part II: Topical Studies in Oceanography 141, 319-328.

de Haan, W.P., Sanchez-Vidal, A., Canals, M., 2019. Floating microplastics and aggregate formation in the Western Mediterranean Sea. Mar Pollut Bull 140, 523-535.

EU, 2008. Marine Strategy Framework Directive (MSFD). 2008/56/EC 
Fossi, M.C., Romeo, T., Baini, M., Panti, C., Marsili, L., Campani, T., Canese, S., Galgani, F., Druon, J.Convergence Areas and Fin Whales Feeding Ground in the Mediterranean Marine Protected Area

Pelagos Sanctuary: A Modeling Approach. Front. Mar. Sci. 4. https://doi.org/10.3389/fmars.2017.00167.

Frias, J., Pagter, E., Nash, R., O’Connor, I., Carretero, O., Filgueiras, A., Viñas, L., J. Gago, Antunes, J.C., Bessa, F., Sobral, P., Goruppi, A., Tirelli, V., Pedrotti, M.L., Suaria, G., Aliani, S., Lopes, C., Raimundo, J., Caetano, M., Palazzo, L., Lucia, G.A.D., Camedda, A., Muniategui, S., Grueiro, G., Fernandez, V., Andrade, J., Dris, R., Laforsch, C., Scholtz-Bottcher, B., Gerdts, G. (2018). Standardised protocol for monitoring microplastics in sediments. https://doi.org/10.13140/rg.2.2.36256.89601/1

Gago, J., Galgani, F., Maes, T., Thompson, R.C., 2016. Microplastics in Seawater: Recommendations from the Marine Strategy Framework Directive Implementation Process. Frontiers in Marine Science 3.

Galgani, F., Giorgetti, A., Vinci, M., Le Moigne, M., Moncoiffe, G., Brosich, A., Molina, E., Lipizer, M., Holdsworth, N., Schlitzer, R., Hanke, G., Schaap, D. (2017). Proposal for gathering and managing data sets on marine micro-litter on a European scale, ver. 21/02/2018, 35 pp., https://doi.org/10.6092/8ce4e8b7-f42c-4683-9ece-c32559606dbd

Galgani, F., 2015. Marine litter, future prospects for research. Frontiers in Marine Science 2. https://doi.org/10.3389/fmars.2015.00087

Galgani, F., Claro, F., Depledge, M., Fossi, C., 2014. Monitoring the impact of litter in large vertebrates in the Mediterranean Sea within the European Marine Strategy Framework Directive (MSFD): Constraints, specificities and recommendations. Mar Environ Res 100, 3-9.

Galgani, F., Hanke, G., Werner, S., De Vrees, L., 2013a. Marine litter within the European Marine Strategy Framework Directive. Ices J Mar Sci 70, 1055-1064.

Galgani, F., Hanke, G., Werner, S., Oosterbaan, L., Nilsson, P., Fleet, D., Kinsey, S., Thompson, R.C., Palatinus, A., Van Franeker, J.A., Vlachogianni, T., Scoullos, M., Veiga, J.M., Matiddi, M., Alcaro, L., Maes, T., Korpinen, S., Budziak, A., Leslie, H.A., Gago, J., Liebezeit, G., 2013b. Guidance on Monitoring of Marine Litter in European Seas. MSFD GES Technical Subgroup on Marine Litter (TSG-ML), in: European Commission, J.R.C., Institute for Environment and Sustainability (Ed.), Luxembourg, p. 124, ISBN: 978-92-79-32709-4

Gerigny, O., Brun, M., Fabri, M.C., Tomasino, C., Le Moigne, M., Jadaud, A., Galgani, F., 2019. Seafloor litter from the continental shelf and canyons in French Mediterranean Water: Distribution, typologies and trends. Mar Pollut Bull 146, 653-666.

GESAMP (2019). Guidelines or the monitoring and assessment of plastic litter and microplastics in the ocean (Kershaw P.J., Turra A. and Galgani F. editors), (IMO/FAO/UNESCOIOC/UNIDO/WMO/IAEA/UN/UNEP/UNDP/ISA Joint Group of Experts on the Scientific Aspects of Marine Environmental Protection). Rep. Stud. GESAMP No. 99, 130p.

Giani, D., Baini, M., Galli, M., Casini, S., Fossi, M.C., 2019. Microplastics occurrence in edible fish species (Mullus barbatus and Merluccius merluccius) collected in three different geographical subareas of the Mediterranean Sea. Mar Pollut Bull 140, 129-137.

Guo, X. and Wang, J., 2019. The chemical behaviors of microplastics in marine environment: A review. Mar Pollut Bull 142, 1-14. 
loakeimidis, C., Galgani, F., Papatheodorou, G., 2017. Occurrence of Marine Litter in the Marine Environment: A World Panorama of Floating and Seafloor Plastics. The Handbook of Environmental Chemistry, vol 78, pp. 1-28. Print ISBN 978-3-319-95566-7

loakeimidis, C., Zeri, C., Kaberi, H., Galatchi, M., Antoniadis, K., Streftaris, N., Galgani, F., Papathanassiou, E., Papatheodorou, G., 2014. A comparative study of marine litter on the seafloor of coastal areas in the Eastern Mediterranean and Black Seas. Mar Pollut Bull, 89, 296-304.

Isobe, A., Buenaventura, N.T., Chastain S., Chavanich S., Cózar A., DeLorenzo, M., Hagmann, P., Hinata, H., Kozlovskii, N., Lusher, A.L., Martí, E., Michida, Y., Mu, J., Ohno, M., Potter, G., Ross, P.S., Sagawa, N., Shim, W.J., Song, Y.K., Takada, H., Tokai, T., Torii, T., Uchida, K., Vassillenko, K., Viyakarn, V., Zhang, W., 2019. An interlaboratory comparison exercise for the determination of microplastics in standard sample bottles. Mar Pollut Bull 146, 831-837.

Jambeck, J.R., Geyer, R., Wilcox, C., Siegler, T.R., Perryman, M., Andrady, A., Narayan, R., Law, K.L., 2015. Plastic waste inputs from land into the ocean. Science 347, 768-771.

Kovač Viršek, M., Palatinus, A., Kaberi, H., Tsangaris, C., Mazziotti, C. (2015). Recommendation on regional approach to monitoring and assessment of microplastic in the marine environment. The document produced within the project DeFishGear (1 $\left.{ }^{\circ} \mathrm{str} / 00010\right)$, IPA Adriatic Cross-border Cooperation Programme 2007 - 2013.

Law, K.L., R., T., 2014. Microplastics in the seas. Science of The Total Environment 345, 144-145.

Lebreton, L.C.M., Greer, S.D., Borrero, J.C., 2012. Numerical modelling of floating debris in the world's oceans. Mar Pollut Bull 64, 653-661.

Li, W.C., Tse, H.F., Fok, L., 2016. Plastic waste in the marine environment: A review of sources, occurrence and effects. Science of The Total Environment 566-567, 333-349.

Limonta, G., Mancia, A., Benkhalqui, A., Bertolucci, C., Abelli, L., Fossi, M.C., Panti, C., 2019. Microplastics induce transcriptional changes, immune response and behavioral alterations in adult zebrafish. Scientific Reports, $9: 15775$.

Maes, T., Perry, J., Alliji, K., Clarke, C., Birchenough, S.N.R., 2019. Shades of grey: Marine litter research developments in Europe. Mar Pollut Bull 146, 274-281.

Michida, Y., Chavanich, S., Cabañas, A.C., Hagmann, P., Hinata, H., Isobe, A., Kershaw, P., Kozlovskii, N., Li, D., Lusher, A.L., , Martí, E., Mason, S.A., Mu, J., Saito, H., Shim, W.J., Syakti, A.D., Takada, H., Richard Thompson, R., Tadashi Tokai, T., Uchida, K., Vasilenko, K., Wang, J., (2019). Guidelines for Harmonizing Ocean Surface Microplastic Monitoring Methods, V1.0., Ministry of the Environment, JAPAN

Miller, M., Kroon, F., Motti, C. (2017). Recovering microplastics from marine samples: A review of current practices. Marine Pollution Bulletin, 123, 6-18.

Panti, C., Giannetti, M., Baini, M., Rubegni, F., Minutoli, R., Fossi, M.C. (2015). Occurrence, relative abundance and spatial distribution of microplastics and zooplankton NW of Sardinia in the Pelagos Sanctuary Protected Area, Mediterranean Sea. Environ. Chem. 12, 618. https://doi.org/10.1071/EN14234 
Peng, L., Fu, D., Qi, H., Lan, C.Q., Yu, H., Ge, C., 2020. Micro- and nano-plastics in marine environment: Source, distribution and threats - A review. Science of The Total Environment 698, 134254.

Prata, J.C., da Costa, J.P., Duarte, A.C., Rocha-Santos, T., 2019a. Methods for sampling and detection of microplastics in water and sediment: A critical review. TrAC Trends in Analytical Chemistry 110, 150-159.

Prata, J.C., da Costa, J.P., Girão, A.V., Lopes, I., Duarte, A.C., Rocha-Santos, T., 2019b. Identifying a quick and efficient method of removing organic matter without damaging microplastic samples. Science of The Total Environment 686, 131-139.

Rochman, C., Browne, M.A., Halpern, B., Hentschel, B., Hoh, E., Karapanagioti, H.K., Rios, L., Takada, H., Teh, S., Thompson, R., 2013. Policy: Classify plastic waste as hazardous. Nature 494, 169-171.

Sharma, S. and Chatterjee, S., 2017. Microplastic pollution, a threat to marine ecosystem and human health: a short review. Environmental science and pollution research international 24, 21530-21547.

Spedicato, M.T., Zupa, W., Carbonara, P., Fiorentino, F., Follesa Maria, C., Galgani, F., García-Ruiz, C., Jadaud, A., loakeimidis, C., Lazarakis, G., Lembo, G., Mandic, M., Maiorano, P., Sartini, M., Serena, F., Cau, A., Esteban, A., Isajlovic, I., Micallef, R., Thasitis, I. 2019; Spatial distribution of marine macrolitter on the seafloor in the northern Mediterranean Sea: the MEDITS initiative. Scientia Marina, Vol 83 , No S1

Stefatos, A., Charalampakis M., Papatheodorou G., Ferentinos G. (1999). Marine Debris on the Seafloor of the Mediterranean Sea: Examples from Two Enclosed Gulfs in Western Greece. Mar Pollut Bull, 38, 389-393.

Sutherland, W.J., Clout, M., Côté, I.M., Daszak, P., Depledge, M.H., Fellman, L., Fleishman, E., Garthwaite, R.I., Gibbons, D.W. , De Lurio, J., Impey A.J., Lickorish, F., Lindenmayer, D., Madgwick, J. , Margerison, C. , Maynard, T. , Peck, L.S. , Pretty, J., Prior, S., Redford, K.H., Scharlemann, J.P.W., Spalding, M., Watkinson, A.R. 2010. A horizon scan of global conservation issues for 2010. Trends in Ecology \& Evolution, 25, 1-7.

Thompson, R.C., Moore, C.J., Saal, F.S.v., Swan, S.H., 2009. Plastics, the environment and human health: current consensus and future trends. Philosophical Transactions of the Royal Society B: Biological Sciences 364, 2153-2166.

UNEP, 2016. Marine plastic debris and microplastics - Global lessons and research to inspire action and guide policy change. United Nations Environment Programme, Nairobi.

UNEP, 2017. Integrated Monitoring and Assessment Programme of the Mediterranean Sea and Coast and Related Assessment Criteria, UN Environment/MAP Athens, Greece.

Van Cauwenberghe, L., Devriese, L., Galgani, F., Janssen, C. (2015). Microplastics in sediments: A review of techniques, occurrence and effects. Marine Environmental Research, 111, 5-17.

Vered, G., Kaplan, A., Avisar, D., Shenkar, N., 2019. Using solitary ascidians to assess microplastic and phthalate plasticizers pollution among marine biota: A case study of the Eastern Mediterranean and Red Sea. Mar Pollut Bull 138, 618-625.

Wesch, C., Bredimus, K., Paulus, M., Klein, R., 2016. Towards the suitable monitoring of ingestion of microplastics by marine biota: A review. Environmental pollution (Barking, Essex: 1987) 218, 12001208. 